\title{
Genetic diversity of the natural populations of Arabidopsis thaliana in China
}

\author{
$\mathrm{F} \mathrm{He}^{1}$, D Kang ${ }^{1}$, Y Ren ${ }^{1}$, L-J Qu ${ }^{1,2}$, Y Zhen ${ }^{1}$ and $\mathrm{H} \mathrm{Gu}^{1,2}$ \\ ${ }^{1}$ Peking-Yale Joint Center for Plant Molecular Genetics and AgroBiotechnology, The National Laboratory of Protein Engineering and \\ Plant Genetic Engineering, College of Life Sciences, Peking University, Beijing, People's Republic of China and ${ }^{2}$ The National Plant Gene \\ Research Center (Beijing), Beijing, People's Republic of China
}

\begin{abstract}
Although extensive studies have been conducted on the genetic structure of Arabidopsis thaliana ( $A$. thaliana) populations worldwide, the populations from China have never been studied. In this study, we collected 560 individuals from 19 natural populations of $A$. thaliana distributed in East China along the lower reaches of the Yangtze River, and two populations from northwest China (Xinjiang Province). We adopted two kinds of molecular marker, inter-simple sequence repeats (ISSRs) and random amplified polymorphic DNA (RAPDs) to investigate the genetic diversity within and among populations, and the correlation between the genetic and geographic distances. Thirteen ISSR primers produced 165 polymorphic bands (PPB) (96\%) and 11 RAPD primers produced 162 polymorphic bands (98\%) in about 560 individuals. The two marker systems generated similar patterns of genetic diversity in these natural populations. The AMOVA analysis
\end{abstract}

indicated about $42-45 \%$ of the total genetic variation existed within populations, and found possible geographic structure. The Mantel test revealed a significant correlation between the geographic distance and the genetic distance of these populations in general. A close genetic relationship was found among four populations in the Jiangxi Province, and these always appeared clustered together as a monophyletic group in unweighted pair-group method with arithmetic averages dendrograms based on both ISSR and RAPD data sets. Based on the observation of recolonization and extinction of naturally distributed populations of $A$. thaliana, and the pattern of their genetic differentiation, the distribution of this species in China might be a result of natural dispersal under the strong influence of human activity.

Heredity (2007) 99, 423-431; doi:10.1038/sj.hdy.6801020; published online 27 June 2007

Keywords: Arabidopsis thaliana; natural populations; China; RAPD; ISSR; genetic diversity

\section{Introduction}

Arabidopsis thaliana (L.) Heynh is an annual, weedy and mostly autogamous species that is native to Europe and central Asia and now naturalized worldwide (AlShehbaz and O'Kane, 2002). Arabidopsis thaliana (A. thaliana) has been adopted as a model organism for establishing an in-depth understanding of plant biology. The use of this species as a model organism has become increasingly important since the elucidation of its genome sequence (The Arabidopsis Genome Initiative, 2000). In addition to a few well-known ecotypes such as Colombia and Landsberg, which have been cultivated in laboratory conditions for plant physiological, developmental, molecular and functional genomic studies, more and more naturally distributed populations (or ecotypes) have been collected and characterized for their genetic variation (King et al., 1993; Innan et al., 1997; Kuittinen et al., 1997; Ullrich et al., 1997; Bergelson et al., 1998; Loridon et al., 1998; Vos, 1998; Breyne et al., 1999; Miyashita et al., 1999; Erschadi et al., 2000; Sharbel et al., 2000; Barth et al., 2002; Hoffmann et al., 2003;

Correspondence: Professor H Gu, College of Life Sciences, Peking University, Beijing 100871, People's Republic of China.

E-mail: guhy@pku.edu.cn

Received 31 January 2007; revised 27 April 2007; accepted 28 May 2007; published online 27 June 2007
Jorgensen and Mauricio, 2004; Nordborg et al., 2005; Stenoien et al., 2005; Schmid et al., 2006). Understanding the amount and distribution of genetic variation between and among populations is not only crucial for ecological and evolutionary studies, but also serves as a base for functional genomic studies. More than 300 accessions collected from different locations around the world are available through Arabidopsis stock centers, such as the Nottingham Arabidopsis Stock Center (NASC) and the Arabidopsis Biological Resource Center (ABRC), which have become an important resource for the Arabidopsisresearch community. The analysis of variants found in nature has proven to be very successful in gaining insight into the control of important processes in plants (Koornneef et al., 2004; Mitchell-Olds and Schmitt, 2006).

Although $A$. thaliana is widely distributed in China, as recorded in the Chinese flora (Cheo et al., 1987, 2001), no accession from China is available in any of the international Arabidopsis stock centers. In China, the herbarium information on this species is fragmental, and the genetic background of the naturally distributed $A$. thaliana is largely unknown. Therefore, it is important to examine the genetic differentiation among the populations in natural habitats in China to construct a broader picture of the genetic diversity of this species around the world. In this study, we collected plant samples from 21 populations of $A$. thaliana from three provinces in East China and one province in Northwest China, and used 
random amplified polymorphic DNA (RAPD) and intersimple sequence repeat (ISSR) markers to investigate the genetic diversity in these populations. The correlation of the geographic distance and genetic distance among these populations was also analyzed.

\section{Materials and methods}

\section{Plant materials}

All naturally distributed populations used in this study were collected by the authors. Nineteen populations were collected from three provinces, Anhui, Jiangxi and Zhejiang in East China, and two populations from Xinjiang Province in Northwest China (Figure 1). The Columbia (Col) ecotype was used for comparison. The locations and habitat descriptions for the naturally distributed populations are listed in Table 1, and each population is denoted by five letters: the first two uppercase letters representing the province followed by three lowercase letters representing the city or county where the population was collected. For example, AHngs represents the population collected in Ningguo City of Anhui Province. For most populations, at least 30 individual plants with matured seeds per population were collected. The whole plants were collected and stored individually in plastic bags with silica gel for immediate drying. However, for some small populations such as the two populations obtained from Xinjiang Province, which had less than 30 individuals per population, only 14-20 individuals were collected. One voucher specimen was collected for each population. Each individual plant was numbered and propagated in a growth room (16 h light, $8 \mathrm{~h}$ dark at $21 \pm 2^{\circ} \mathrm{C}$ ).

\section{DNA isolation}

The total DNA was isolated from the rosette leaves of the silica-dried materials (for ISSR analysis) or from the plants propagated in a greenhouse (for RAPD analysis). For the fresh materials, the CTAB method was adopted (Qu et al., 2000); while for the silica-dried materials, the plant materials were pretreated with 1.5\% PVP and proteinase $\mathrm{K}$, and then treated by the CTAB method. For each population (including Col ecotype), the DNA was isolated from 14 to 30 individuals separately.

\section{ISSR and RAPD analysis}

Twelve ISSR primers were chosen from those primers previously used by Barth et al. (2002), while another five were designed based on the Arabidopsis genome sequence (The Arabidopsis Genome Initiative, 2000). In total, 17 primers were used for a two-step primer screening process. For the first step, the total DNA obtained from Col ecotype was used to identify the primers that produced clear and reproducible bands. For the second step, six individuals from each population were randomly selected for RAPD analysis with primers selected in the first step. Following the two-step primer screening, 13 primers with clear and reproducible bands were chosen for the amplification reactions for all individuals in the present study (Table 2). PCR amplification was carried out in $25 \mu \mathrm{l}$ with $20 \mathrm{mM}$ Tris- $\mathrm{HCl}$, $10 \mathrm{mM}\left(\mathrm{NH}_{4}\right)_{2} \mathrm{SO}_{4}, 10 \mathrm{mM} \mathrm{KCl}, 0.1 \%$ Triton X-100 (pH 8.8), $2 \mathrm{mM} \mathrm{MgCl}_{2}, 200 \mu \mathrm{M}$ each of dATP, dGTP, dCTP and dTTP, 0.4 pmol of primer, $0.8 \mathrm{U}$ Taq DNA polymerase (Dingguo Biotech, Beijing, China) and $20 \mathrm{ng}$ template DNA. Thermal cycling (Thermocycler PTC-225, MJ Research, Watertown) started with $5 \mathrm{~min}$ at $94^{\circ} \mathrm{C}$, and 45 cycles of $1 \mathrm{~min}$ at $94^{\circ} \mathrm{C}, 45 \mathrm{~s}$ at $50^{\circ} \mathrm{C}$ and $2 \mathrm{~min}$ at $72^{\circ} \mathrm{C}$ and ended by an extension for $7 \mathrm{~min}$ at $72^{\circ} \mathrm{C}$. The amplification products were separated on $1.4 \%$ agarose gels in TAE buffer for about $4 \mathrm{~h}(5-7 \mathrm{~V} / \mathrm{cm})$, stained with ethidium bromide and documented using an AmpGene Gel 100 system. The $100 \mathrm{bp}$ ladder marker (Promega (Beijing) Biotech Co. Ltd, China) and $\lambda \mathrm{DNA} / E c o R I+$ HindIII marker were used as size standards.

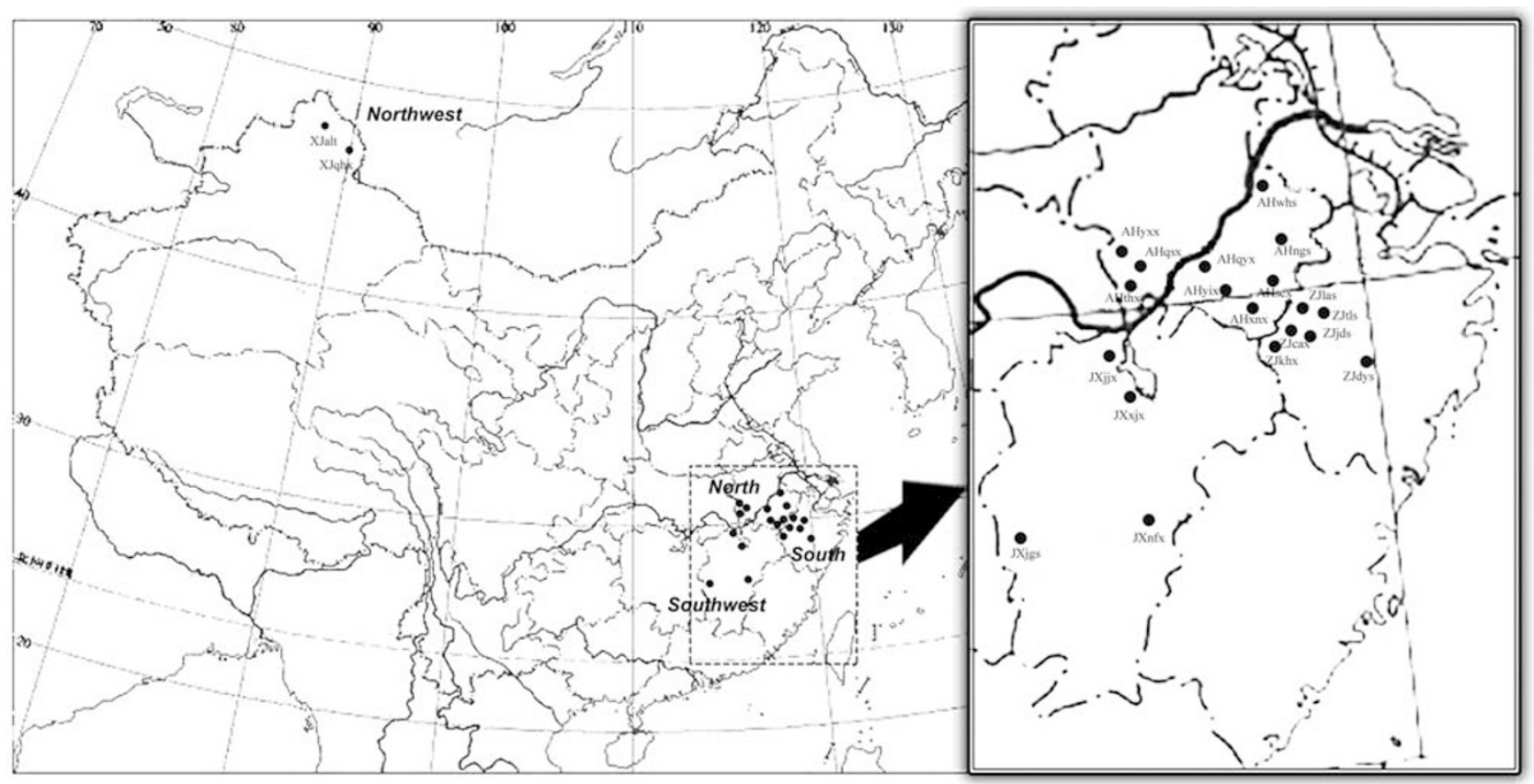

Figure 1 Distribution map of the populations of Arabidopsis thaliana used in this study. 
Table 1 Naturally distributed populations collected in China

\begin{tabular}{|c|c|c|c|c|}
\hline Group & Location & Latitude and longitude & Altitude $(m)$ & Habitat \\
\hline \multirow[t]{12}{*}{ South } & Anhui, ningguoshi (AHngs) & $30^{\circ} 41.08 \mathrm{~N} 118^{\circ} 58.36 \mathrm{E}$ & 160 & River side, naked area \\
\hline & Anhui, qingyangxian (AHqyx) & $30^{\circ} 37.15 \mathrm{~N} 117^{\circ} 45.39 \mathrm{E}$ & 70 & River side, field border \\
\hline & Anhui, shexian (AHsex) & $29^{\circ} 51.02 \mathrm{~N} 118^{\circ} 22.75 \mathrm{E}$ & 200 & Railway bed \\
\hline & Anhui, wuhushi (AHwhs) & $31^{\circ} 23.13 \mathrm{~N} 118^{\circ} 22.74 \mathrm{E}$ & 20 & Field border near railway \\
\hline & Anhui, xiuningxian (AHxnx) & $29^{\circ} 47.78 \mathrm{~N} 118^{\circ} 10.50 \mathrm{E}$ & 310 & Railway slope \\
\hline & Anhui, yixian (AHyix) & $29^{\circ} 57.48 \mathrm{~N} 117^{\circ} 57.32 \mathrm{E}$ & 420 & Farmland \\
\hline & Zhejiang, chun'anxian (ZJcax) & $29^{\circ} 48.28 \mathrm{~N} 118^{\circ} 50.97 \mathrm{E}$ & 100 & Near the rivulet, road side \\
\hline & Zhejiang, dongyangshi (ZJdys) & $29^{\circ} 05.02 \mathrm{~N} 120^{\circ} 25.65 \mathrm{E}$ & 290 & Field border \\
\hline & Zhejiang, jiandeshi (ZJjds) & $29^{\circ} 32.13 \mathrm{~N} 119^{\circ} 29.61 \mathrm{E}$ & 100 & Bank near a river \\
\hline & Zhejiang, kaihuaxian (ZJkhx) & $29^{\circ} 06.50 \mathrm{~N} 118^{\circ} 23.03 \mathrm{E}$ & 165 & Road side near the river \\
\hline & Zhejiang, lin'anshi (ZJlas) & $30^{\circ} 03.16 \mathrm{~N} 119^{\circ} 54.88 \mathrm{E}$ & 420 & Near the rivulet \\
\hline & Zhejiang tonglushi (ZJtls) & $29^{\circ} 41.39 \mathrm{~N} 119^{\circ} 39.90 \mathrm{E}$ & 210 & Road side near the river \\
\hline \multirow[t]{4}{*}{ Southwest } & Jiangxi, jingganshan (JXjgs) & $26^{\circ} 44.78 \mathrm{~N} 114^{\circ} 17.98 \mathrm{E}$ & 390 & Near the rivulet \\
\hline & Jiangxi, jiujiangxian (JXjjx) & $29^{\circ} 35.68 \mathrm{~N} 115^{\circ} 54.74 \mathrm{E}$ & 80 & Road side along the river \\
\hline & Jiangxi, nanfengxian (JXnfx) & $26^{\circ} 59.18 \mathrm{~N} 116^{\circ} 14.51 \mathrm{E}$ & 360 & River side \\
\hline & Jiangxi, xinjianxian (JXxjx) & $28^{\circ} 44.33 \mathrm{~N} 115^{\circ} 44.11 \mathrm{E}$ & 100 & Near the rivulet, naked area \\
\hline \multirow[t]{3}{*}{ North } & Anhui, qianshanxian (AHqsx) & $30^{\circ} 44.77 \mathrm{~N} 117^{\circ} 37.43 \mathrm{E}$ & 150 & Road side \\
\hline & Anhui, taihuxian (AHthx) & $30^{\circ} 27.80 \mathrm{~N} 117^{\circ} 17.79 \mathrm{E}$ & 120 & Railway bed \\
\hline & Anhui, yuexixian (AHyxx) & $30^{\circ} 42.89 \mathrm{~N} 116^{\circ} 15.33 \mathrm{E}$ & $600-800$ & Road side \\
\hline \multirow[t]{2}{*}{ Northwest } & Xinjiang, aletaishi (XJalt) & $47^{\circ} 46.72 \mathrm{~N} 88^{\circ} 20.64 \mathrm{E}$ & 830 & Sandy grassplot near the river \\
\hline & Xinjiang, qinghexian (XJqhx) & $46^{\circ} 48.72 \mathrm{~N} 90^{\circ} 20.39 \mathrm{E}$ & 1400 & Rivulet side in the valley \\
\hline
\end{tabular}

Table 2 The ISSR primers and the polymorphism of their PCR products

\begin{tabular}{lccc}
\hline $\begin{array}{l}\text { Primer } \\
\text { sequence }\end{array}$ & Total bands & $\begin{array}{c}\text { Polymorphic } \\
\text { bands }\end{array}$ & $\begin{array}{c}\text { Shannon's information } \\
\text { index }\end{array}$ \\
\hline (AG)8T & 12 & 12 & 0.4207 \\
(TC)8A & 13 & 12 & 0.3403 \\
(AC)8G & 14 & 13 & 0.3277 \\
(AC)8(CT)T & 17 & 17 & 0.4163 \\
(AC)8(CT)G & 13 & 13 & 0.2895 \\
(TG)8(AG)A & 13 & 12 & 0.2297 \\
(ATG)5 & 16 & 15 & 0.2182 \\
(AGC)4G(AG) & 16 & 15 & 0.3047 \\
(AC)8T & 11 & 11 & 0.3432 \\
(GAA)6 & 12 & 12 & 0.5179 \\
(GGAGA)3 & 8 & 8 & 0.4259 \\
(GCT)4(CT) & 18 & 17 & 0.4137 \\
(CA)6(AG) & 9 & 8 & 0.2723 \\
\hline
\end{tabular}

For RAPD analysis, 153 primers (S2001 S2100, S201 220, S401 S420, S480 S500, Sangon Co. Ltd, Shanghai, China) were screened using the same procedure as in the ISSR analysis. Eleven primers with clear and reproducible bands were selected (Table 3 ). The procedure of PCR amplification and its product documentation for RAPD analysis were the same as that used in the ISSR analysis with only a slight modification in the thermal cycles: a hot start for $7 \mathrm{~min}$ at $94^{\circ} \mathrm{C}$, and 45 cycles of $45 \mathrm{~s}$ at $94^{\circ} \mathrm{C}, 1 \mathrm{~min}$ at $36^{\circ} \mathrm{C}$ and $2 \mathrm{~min}$ at $72^{\circ} \mathrm{C}$ and ended by an extension of $7 \mathrm{~min}$ at $72^{\circ} \mathrm{C}$.

\section{Data analysis}

The amplified RAPD and ISSR fragments were scored for the presence or absence of bands ( $1=$ present, $0=$ absent). Only clear and reproducible bands were scored. Each of the bands (DNA fragments) was considered a single, unique locus with Mendelian segregation. A locus was considered polymorphic if the relevant band was present in one or more, but not all, individuals of the population. A two-dimensional matrix was generated for each of the two molecular marker systems. The percentage of polymorphic bands (PPB) was calculated from the matrix by the number of PBs/ total number of bands $\times 100 \%$. The Shannon's Information Index (Lewontin, 1972), $I=1-\Sigma p i l n p i$, was calculated for the genetic diversity in natural populations, where $p i$ is the frequency of the $i$ th band. Nei (1973), measurements of genetic diversity among natural populations were also calculated, including the total genetic diversity (that is, expected heterozygosity) $\left(H_{\mathrm{T}}\right)$, mean genetic diversity within populations $\left(H_{\mathrm{S}}\right)$, and the proportion of genetic diversity occurring among populations, $G_{\mathrm{ST}}=\left(H_{\mathrm{T}}-H_{\mathrm{S}}\right) / H_{\mathrm{T}}(\mathrm{Nei}, 1973)$. All of these genetic diversity parameters were estimated using POPGENE version 1.32 (Yeh et al., 1999). The 21 natural populations were divided into four geographic groups: the northwestern group (two Xinjiang populations in the most northwestern part of China), which is geographically far from the other populations; the northern group (three populations north of the Yangtze River in the Anhui Province), southwestern group (four populations south of the Yangtze River in the Jiangxi Province), and southern group (the remaining populations south of the Yangtze River in the Anhui and Zhejiang Provinces). The southwestern group is separated from the southern group by Poyang Lake, the largest freshwater lake in China. The genetic variation among the natural populations was also estimated from the analysis of molecular variance (AMOVA) (Excoffier et al., 1992), in which the total genetic variance was partitioned into 'among population' and 'within population' components. The Hillis distance was calculated between each pair of individuals (Hillis, 1984). The genetic relationships among the natural populations were estimated using 
the unweighted pair-group method with arithmetic averages (UPGMA). Cophenetic values $\left(r_{\mathrm{cp}}\right)$ based on the results of the UPGMA cluster analysis were calculated as a measure of the quality of clustering (Rohlf, 1982). The Mantel test (Mantel, 1967) was used to test the correspondence between RAPD and ISSR marker-based similarity matrices (Lapointe and Legendre, 1992), and to test the correlation between the geographical distance and genetic distance (Sharbel et al., 2000). The geographic distance was defined by GIS, and was calculated using the World Book Atlas module in IBM Book MAC Edition (version 2004). These calculations were carried out using NTSYS-pc version 2.11Q (Rohlf, 2002).

Table 3 The RAPD primers and the polymorphism of their PCR products

\begin{tabular}{llccc}
\hline $\begin{array}{l}\text { Primer } \\
\text { order }\end{array}$ & Primer sequence & $\begin{array}{c}\text { Total } \\
\text { bands }\end{array}$ & $\begin{array}{c}\text { Polymorphic } \\
\text { bands }\end{array}$ & $\begin{array}{c}\text { Shannon's } \\
\text { information } \\
\text { index }\end{array}$ \\
\hline S97 & ACGACCGACA & 10 & 9 & 0.1843 \\
S2002 & TGCTCGGCTC & 18 & 17 & 0.2696 \\
S2006 & GGACGACCGT & 14 & 13 & 0.3307 \\
S2055 & CCAGACTCCA & 15 & 15 & 0.3517 \\
S2056 & CTGGTGCTCA & 15 & 15 & 0.4348 \\
S2064 & TCGGGTGTTG & 11 & 11 & 0.5017 \\
S2075 & TGTCGTGGTC & 15 & 15 & 0.3755 \\
S2080 & AGGCGGCACA & 16 & 16 & 0.4820 \\
S2083 & TGGACTCGGT & 17 & 17 & 0.3338 \\
S2097 & GGGAAAAGCC & 18 & 18 & 0.3983 \\
S2099 & AGGCCAACAG & 18 & 18 & 0.3832 \\
\hline
\end{tabular}

\section{Results}

Thirteen ISSR primers produced 172 scorable bands in 566 individuals of 21 natural populations and Col ecotype, with 13.24 bands per primer in average ranging from 8 (by primer $(A C)_{8}$ ) to 18 bands (by primer $\left.(\mathrm{GCT})_{4}(\mathrm{CT})\right)$. Among the total number of bands, $95.93 \%$ (165) were polymorphic (Table 2), and 6.98\% (12) were not significantly different among populations $(P>0.05)$ while $85.47 \%$ (147) were significantly different $(P<0.001)$. For the RAPD analysis, 11 primers yielded 165 reliable bands in the 560 individuals of 21 natural populations and Col ecotype, with 15 bands per primer in average ranging from 10 (by primer S2002) to 18 bands (by primers S97, S2006 and S2083). Of the bands, 98.18\% (162) were polymorphic (Table 3) and 7.78\% (13) were not significantly different among populations $(P>0.05)$ while $83.63 \%$ (138) were significantly different $(P<0.001)$. In both cases, more than $50 \%$ of the polymorphic fragments occurred at frequencies less than 0.10. For the ISSR markers, the mean percentage of PPB within natural populations was $35.94 \%$, ranging from $18.60 \%$ (JXnfx) to $56.40 \%$ (AHyix) (Table 4). Geographically, the four southwestern populations were found to have low PPBs, while the populations in Anhui Province had relatively high PPBs in both the north and south groups. Two individuals from JXjgs and JXnfx respectively were determined to have identical banding profiles, but no identical profile was shared by individuals from different populations. For the RAPD markers, the mean PPB was $35.38 \%$, ranging from $21.21 \%$ (ZJdys,

Table 4 Genetic diversity of the natural populations from China based on ISSR and RAPD data sets

\begin{tabular}{|c|c|c|c|c|c|c|c|c|c|}
\hline \multirow[t]{2}{*}{ Group } & \multirow[t]{2}{*}{ Population } & \multicolumn{4}{|c|}{ ISSR } & \multicolumn{4}{|c|}{$R A P D$} \\
\hline & & Sample size & Polymorphic bands & $P P B(\%)$ & $I^{\mathrm{a}}$ & Sample size & Polymorphic bands & $P P B(\%)$ & $I^{\mathrm{a}}$ \\
\hline \multirow{12}{*}{ South } & AHngs & 29 & 85 & 49.42 & 0.2529 & 29 & 82 & 49.70 & 0.2403 \\
\hline & AHqyx & 29 & 72 & 41.86 & 0.2242 & 29 & 70 & 42.42 & 0.2003 \\
\hline & AHsex & 31 & 71 & 41.28 & 0.2212 & 29 & 44 & 26.67 & 0.1321 \\
\hline & AHwhs & 29 & 71 & 41.28 & 0.2014 & 29 & 69 & 41.82 & 0.1897 \\
\hline & AHxnx & 29 & 83 & 48.26 & 0.2402 & 28 & 67 & 40.61 & 0.1974 \\
\hline & AHyix & 30 & 97 & 56.40 & 0.2940 & 29 & 88 & 53.33 & 0.2669 \\
\hline & ZJcax & 26 & 68 & 39.53 & 0.1831 & 26 & 60 & 36.36 & 0.1849 \\
\hline & ZJdys & 16 & 49 & 28.49 & 0.1385 & 16 & 21 & 21.21 & 0.1109 \\
\hline & ZJjds & 23 & 42 & 24.42 & 0.1430 & 23 & 63 & 38.18 & 0.1755 \\
\hline & ZJkhx & 29 & 55 & 31.98 & 0.1562 & 29 & 40 & 24.24 & 0.1386 \\
\hline & ZJlas & 14 & 55 & 31.98 & 0.1751 & 13 & 44 & 26.67 & 0.1393 \\
\hline & ZJtls & 17 & 50 & 29.07 & 0.1546 & 17 & 52 & 31.52 & 0.1815 \\
\hline \multirow[t]{4}{*}{ Southwest } & JXjgs & 28 & 43 & 25.00 & 0.1229 & 28 & 69 & 41.82 & 0.1857 \\
\hline & JXjjx & 30 & 38 & 22.09 & 0.1057 & 29 & 55 & 33.33 & 0.1477 \\
\hline & JXnfx & 30 & 32 & 18.60 & 0.0966 & 30 & 47 & 28.48 & 0.1228 \\
\hline & $\mathrm{JXxjx}$ & 29 & 48 & 27.91 & 0.1468 & 30 & 61 & 36.97 & 0.1797 \\
\hline \multirow[t]{3}{*}{ North } & AHqsx & 30 & 82 & 47.67 & 0.2350 & 30 & 63 & 38.18 & 0.1781 \\
\hline & AHthx & 27 & 89 & 51.74 & 0.2580 & 28 & 78 & 47.27 & 0.2234 \\
\hline & AHyxx & 30 & 59 & 34.30 & 0.1791 & 30 & 69 & 41.82 & 0.1968 \\
\hline \multirow[t]{2}{*}{ Northwest } & XJalt & 16 & 55 & 31.98 & 0.1759 & 14 & 35 & 21.21 & 0.1248 \\
\hline & XJqhx & 15 & 54 & 31.40 & 0.1840 & 15 & 21 & 21.21 & 0.1231 \\
\hline Col & & 29 & 13 & 7.56 & 0.0411 & 29 & 32 & 19.39 & 0.0999 \\
\hline Species & & 566 & 165 & 95.93 & 0.3462 & 560 & 162 & 98.18 & 0.3698 \\
\hline
\end{tabular}

Abbreviations: ISSR, inter-simple sequence repeat; PPB, percentage of polymorphic bands; RAPD, random amplified polymorphic DNA. aI, Shannon's information index. 
XJalt and XJqhx) to 53.33\% (AHyix) (Table 4). Two populations from the northwest group and one from the south group (ZJdys) have the lowest PPB among the natural populations, while the populations from Anhui province have relatively high PPBs in both the north and south groups. Two individuals from JXnfx, JXjjx and JXxjx, respectively, have identical banding profiles, but no identical profile was shared by individuals from different populations. Compared to the natural populations, the Col ecotype has the lowest PPB, as revealed by both the ISSR and RAPD markers. The mean Shannon's Information index within natural populations was 0.1852, ranging from 0.0966 (JXnfx) to 0.2940 (AHyix) for ISSR markers; and 0.1733, ranging from 0.1109 (ZJdys) to 0.2669 (AHyix) for RAPD markers (Table 4).

At population level, the genetic diversity of all populations is 0.4267 as detected by using ISSR markers, and 0.4946 by RAPD markers. At the group level, both ISSR and RAPD markers detected the lowest genetic diversity in the northwest group. However, ISSR markers detected the highest genetic diversity in the southwest group $\left(G_{\text {st }}=0.3372\right)$, while RAPD detected the highest diversity in the south group $\left(G_{\text {st }}=0.4768\right)$. The AMOVA analysis detected about 54 and $58 \%$ of the variation due to the genetic variation among populations based on the ISSR and RAPD data sets, respectively (Table 5). It is interesting to note that at group level, in contrast to population level, less genetic variation was found among populations, as revealed by both ISSR and RAPD markers, except for the southern group where more genetic variation was found among populations as detected by RAPD markers. For example, in the northern group, only about 41 and 39\% of variation is found among populations revealed by ISSR and RAPD markers, respectively. Further analysis indicated that this resulted from a relatively high proportion of genetic variation among the groups (Table 5).

UPGMA dendrograms based on the Hillis distance matrixes generated from the raw data of the ISSR or RAPD markers did not group the populations exactly according to their geographic distribution. However, the four populations of the southwestern group were always clustered together in both ISSR and RAPD dendrograms as a monophyletic group (Figures 2 and 3). Although two of the populations in the northwestern group were always clustered together, it is interesting to note that these two were also clustered with some populations in the southern group. The Col ecotype was the basal group' in both the ISSR and RAPD dendrograms. The cophenetic values $\left(r_{\mathrm{cp}}\right)$ of the UPGMA clustering based on the ISSR and RAPD data sets was significantly correlated to the primary data matrixes of ISSR and RAPD, respectively $\left(r_{\mathrm{cp}}=0.80793\right.$ for ISSR data set and $r_{\mathrm{cp}}=0.91622$ for RAPD data set).

The Mantel test on the ISSR data set indicated that the geographical distance was significantly correlated with the genetic distance $\left(r_{\mathrm{cp}}=0.58924, P<0.001\right)$ when using the complete data set (including $\mathrm{Col}$ ). When $\mathrm{Col}$ or $\mathrm{Col}$ and the Xinjiang's populations were excluded from the data set respectively, the correlations were still significant $\left(r_{\mathrm{cp}}=0.37952, \quad P<0.005\right.$ and $r_{\mathrm{cp}}=0.49100, \quad P<0.0001$ respectively). Similar correlations were also found for the RAPD data set when the Mantel test was applied $\left(r_{\mathrm{cp}}=0.71907, P<0.00001\right.$ for complete data set; $r_{\mathrm{cp}}=0.32985, P<0.01$ excluding Col; $r_{\mathrm{cp}}=0.30710$,
$P<0.02$ excluding $\mathrm{Col}$ and Xinjiang's populations). The Mantel test also detected a significant correspondence between the genetic similarities based on the ISSR and RAPD data sets $\left(r_{\mathrm{cp}}=0.6792, P<0.00001\right)$.

\section{Discussion}

\section{The distribution and natural habitats of Arabidopsis thaliana in China}

A. thaliana is widely distributed in China and has been recorded in Eastern, Central, Northwestern, Western and Southwestern China (Cheo et al., 1987, 2001), covering both temperate and subtropical zones. Although $A$. thaliana has a wide distribution in China, relatively few herbarium specimens are found in this country. The earliest dated specimens we examined were collected from Yixian County, Anhui Province, in 1910 and deposited in the herbarium of the Institute of Botany, Beijing (PE). This lack of herbarium specimens may partially be attributed to the fact that this species has very short flowering-fruiting times, usually in early spring and/or that it is an inconspicuous weedy species.

The habitats of the natural populations of $A$. thaliana collected for this study are diverse, such as from along the roadside or from farmland, slopes or abandoned fields, with altitudes ranging from $20 \mathrm{~m}$ (AHthx) to $1400 \mathrm{~m}$ (XJqhx). The populations are usually distributed in relatively moist areas. The two populations from Xinjiang Province (XJqhx and XJalt) were obtained from the Altai Mountain range. Among the samples collected for this study, the XJqhx and XJalt populations grow at the highest altitude and lowest temperature during the growth season. When the authors collected samples from Qinghe (XJqhx) in early June, it was during a period of snowfall. The phenotype of the plants varies greatly in the fields. For example, the average height of individuals of the northwestern group is $16-18 \mathrm{~cm}$, while that of the southern group is $26-46 \mathrm{~cm}$. When the individuals from different populations were planted in the greenhouse at $22 \pm 2^{\circ} \mathrm{C}$, those in the northwest group tended to flower earlier than the populations from East China.

These natural populations are usually found in disturbed habitats with strong influences of human activity. It seems that some newly found distributions could be attributed to human-aided dispersal. Since $A$. thaliana produces numerous tiny seeds, wind could also cause long-distance dispersal (Tackenberg et al., 2003; Jorgensen and Mauricio, 2004). The dynamic distribution pattern of $A$. thaliana in East China might reflect a history of combination of natural and human-aided dispersal.

\section{Comparison of the results based on RAPD and ISSR data sets}

Although there have been many debates on the reproducibility of RAPD markers, many studies have shown that RAPDs are useful molecular markers to detect genetic diversity at the population level in wellcontrolled experiments (Bartish et al., 2000; Diaz et al., 2001; Reisch et al., 2003; Fontaine et al., 2004; Nybom, 2004). Since the ISSR markers are generated by longer primers (15-24 bp), these were thought to be more stable than the RAPD markers (Yang et al., 1996; Nagaoka and Ogihara, 1997; Parsons et al., 1997; Esselman et al., 1999). In this study, the reproducibility of RAPD and ISSR was 
Table 5 Genetic variations within and among populations revealed by AMOVA based on ISSR and RAPD data sets

\begin{tabular}{|c|c|c|c|c|c|c|c|c|c|c|}
\hline \multirow[t]{2}{*}{ Source of variation } & \multicolumn{5}{|c|}{ ISSR } & \multicolumn{5}{|c|}{$R A P D$} \\
\hline & d.f. & Sum of squares & Variance components & Percentage of variation & P-value & d.f. & Sum of squares & Variance components & Percentage of variation & P-value \\
\hline \multicolumn{11}{|l|}{ South group } \\
\hline Among populations & 11 & 1868.169 & 6.38303 & 39.00 & $P<0.001$ & 11 & 2683.812 & 9.56261 & 53.02 & $P<0.001$ \\
\hline Within populations & 92 & 2895.632 & 9.98494 & 61.00 & $P<0.001$ & 285 & 2415.111 & 8.47407 & 46.98 & $P<0.001$ \\
\hline \multicolumn{11}{|l|}{ Southwest group } \\
\hline Among populations & 3 & 363.572 & 3.99176 & 47.21 & $P<0.001$ & 3 & 352.698 & 3.82326 & 39.87 & $P<0.001$ \\
\hline Within populations & 111 & 504.309 & 4.46291 & 52.79 & $P<0.001$ & 113 & 651.508 & 5.76555 & 60.13 & $P<0.001$ \\
\hline \multicolumn{11}{|l|}{ North group } \\
\hline Among populations & 2 & 427.481 & 7.02520 & 40.66 & $P<0.001$ & 2 & 357.032 & 5.78348 & 39.24 & $P<0.001$ \\
\hline Within populations & 84 & 861.185 & 10.25220 & 59.34 & $P<0.001$ & 5 & 761.150 & 8.95471 & 60.76 & $P<0.001$ \\
\hline \multicolumn{11}{|l|}{ Northwest group } \\
\hline Among populations & 1 & 90.885 & 5.28773 & 36.98 & $P<0.001$ & 1 & 43.801 & 2.64236 & 32.32 & $P<0.001$ \\
\hline Within populations & 29 & 261.308 & 9.01063 & 63.02 & $P<0.001$ & 27 & 149.371 & 5.53228 & 67.68 & $P<0.001$ \\
\hline \multicolumn{11}{|l|}{ East China } \\
\hline Among groups & 2 & 1586.248 & 4.32132 & 22.68 & $P<0.001$ & 2 & 1231.218 & 2.70323 & 14.65 & $P<0.001$ \\
\hline Within groups & 16 & 2659.222 & 5.98210 & 31.40 & $P<0.001$ & 16 & 3393.541 & 7.82881 & 42.42 & $P<0.001$ \\
\hline Within populations & 487 & 4261.125 & 8.74974 & 45.92 & $P<0.001$ & 483 & 3827.768 & 7.92499 & 42.94 & $P<0.001$ \\
\hline \multicolumn{11}{|l|}{ China } \\
\hline Among groups & 3 & 1972.475 & 4.63004 & 23.93 & $P<0.001$ & 3 & 1627.269 & 3.24804 & 17.37 & $P<0.001$ \\
\hline Within groups & 17 & 2750.108 & 5.95750 & 30.79 & $P<0.001$ & 17 & 3428.617 & 7.63584 & 40.83 & $P<0.001$ \\
\hline Within populations & 516 & 4522.434 & 8.76441 & 45.29 & $P<0.001$ & 510 & 3985.864 & 7.81542 & 41.80 & $P<0.001$ \\
\hline
\end{tabular}

Abbreviations: ISSR, inter-simple sequence repeat; RAPD, random amplified polymorphic DNA. 


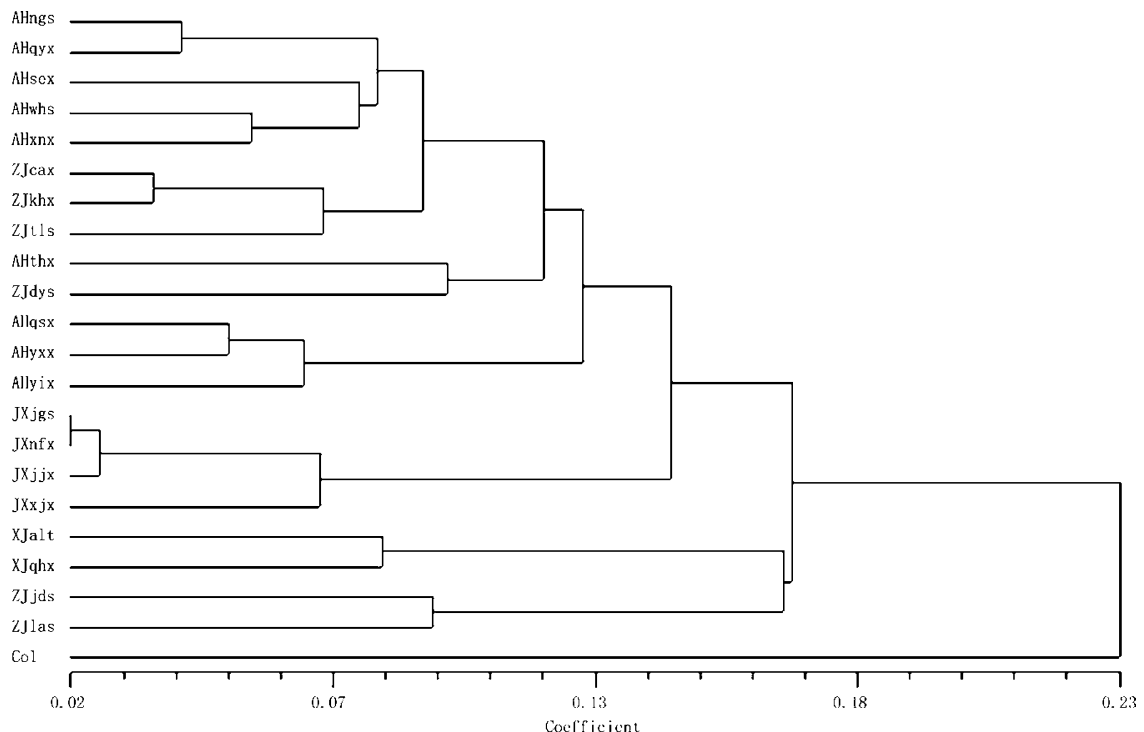

Figure 2 Unweighted pair-group method with arithmetic averages clustering of Arabidopsis thaliana based on Hillis distance calculated from inter-simple sequence repeats data set.

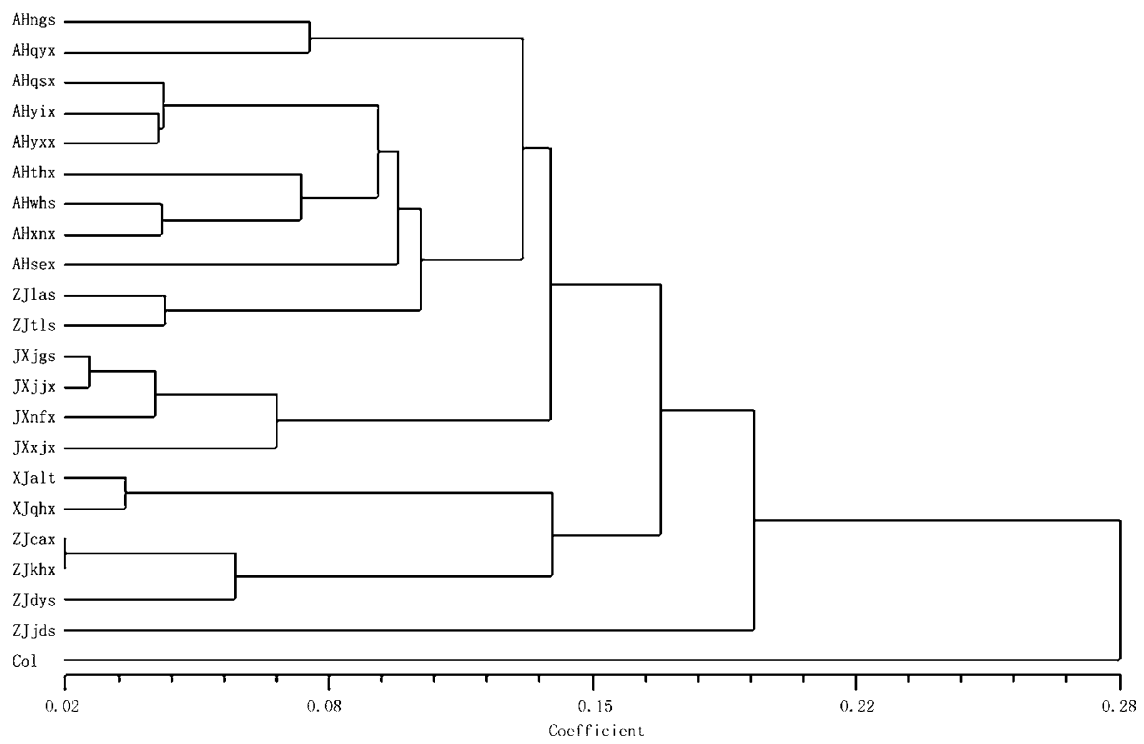

Figure 3 Unweighted pair-group method with arithmetic averages clustering of Arabidopsis thaliana based on Hillis distance calculated from random amplified polymorphic DNA data set.

assured by a repeated PCR amplification for at least six individuals in each population. Both ISSR and RAPD amplifications produced stable and repeatable fragments by the selected primers. In general, the ISSR and RAPD markers generated similar results on the genetic diversity within and among the natural populations, as revealed by Nei's measurement (Nei, 1973) of genetic diversity and AMOVA analysis. Moreover, the UPGMA clustering based on these two data sets were significantly correlated to their distance data matrixes respectively, although the $r_{\mathrm{cp}}$ value of ISSR $\left(r_{\mathrm{cp}}=0.80793\right)$ is lower than that of RAPD $\left(r_{\mathrm{cp}}=0.91622\right)$.

\section{Genetic variation among and within populations}

Although extensive studies have been conducted on the genetic diversity of $A$. thaliana around the world, none of the populations from China have ever been included. This study is focused on the genetic diversity of naturally distributed populations in China. The overall genetic diversity of the 21 natural populations, $G_{\text {st }}=0.4946$ $(\mathrm{RAPD}), G_{\mathrm{st}}=0.4267$ (ISSR), was approximately the same as that seen in other selfing species with gravitydispersed seeds, whose average $G_{\text {st }}=0.5$ (Hamrick and Godt, 1996), less than that of the native North European populations $\left(F_{\mathrm{st}}=0.88\right.$; Stenoien et al, 2005) or native populations in France $\left(F_{\mathrm{st}}=0.59\right.$; Le Corre, 2005), but significantly greater than that of the North American populations $\left(G_{\mathrm{st}}=0.28\right)$ reported by Jorgensen and Mauricio (2004). When the northwestern populations were excluded, the genetic divergence of the 19 East China populations reduced only slightly (data not shown). Although $A$. thaliana was introduced into East China (Al-Shehbaz and O'Kane, 2002), its overall genetic 
diversity is much greater than those recently introduced populations in North America, but still less than those native populations in Europe. This finding might indicate that the populations in China have a longer 'introduction' history than those in North America, which could also be supported by the fact that no identical banding profile was found between/among individuals of different populations. When the genetic variation is dissected into 'within' and 'among' population variations, typically, selfing species have low levels of genetic diversity within populations, but a substantial differentiation among populations (Hamrick and Godt, 1996). In previous studies, the hierarchical AMOVA on the genetic variation of the natural population of $A$. thaliana revealed different patterns for different populations. In most cases, the observed genetic variation was consistent with its lifestyle: less variation existed within populations and more genetic variation was found among populations (Hanfstingl et al., 1994; Bergelson et al., 1998; Breyne et al., 1999; Miyashita et al., 1999; Jorgensen and Mauricio, 2004; Stenoien et al., 2005). For example, Stenoien et al. (2005) found that, on average, only $12 \%$ of the genetic variation occurred among individuals within 10 northern European populations of $A$. thaliana, as screened by microsatellite markers. In other cases, higher genetic variation was found within populations than among populations. For example, Jorgensen and Mauricio (2004) detected that approximately $77 \%$ of the genetic variation occurred among individuals within six North American populations, as revealed by AFLP markers; and Bakker et al. (2006) found $56.7 \%$ of genetic variation within populations by the sequences of six genes and five microsatellite loci over the species range. In this study, in the hierarchical AMOVA for the 21 Chinese populations, it was found that slightly more genetic variation occurred among populations rather than within populations, as revealed by ISSR $(54.7 \%)$ and RAPD (58.2\%) makers, respectively. When two Xinjiang populations were excluded, the genetic variations within 19 Chinese populations were similar to that within 21 populations (Table 5). Although it is difficult to compare directly the results of the studies mentioned above due to different population size and methodology being adopted, the general trend can be referred. The relatively high amount of genetic variation found among groups of Chinese populations may indicate a geographic structure.

\section{The correlation of genetic and geographic distance}

The correlation between the genetic distance of populations and their geographic distance has been discussed extensively in previous studies using various molecular markers in A. thaliana. In most cases, no clear association between geographical origin and genetic similarity was detected in populations distributed in different regions of the world (King et al., 1993; Hanfstingl et al., 1994; Innan et al., 1997; Ullrich et al., 1997; Bergelson et al., 1998; Loridon et al., 1998; Breyne et al., 1999; Miyashita et al., 1999; Erschadi et al., 2000; Jorgensen and Mauricio, 2004; Stenoien et al., 2005; Bakker et al., 2006). However, Sharbel et al. (2000) detected significant, but weak, isolation by distance among populations sampled from the presumed native range of A. thaliana in Eurasia; and Barth et al. (2002) found some Asian accessions clustered separately from the central European plants. A recent study by Nordborg et al. (2005) on the fragments of $480 \mathrm{~kb}$ obtained from each of 96 individual genomes revealed a strong population structure, despite the fact that individual populations harbor much of the variation present species-wide. In this study, generally significant correlations between the geographical and genetic distance were detected using the Mantel test for Chinese populations, based on both ISSR and RAPD markers $(P<0.005$ for ISSR and $P<0.01$ for RAPD) and for the eastern Chinese populations $(P<0.01$ for ISSR and $P<0.02$ for RAPD)

Although $A$. thaliana is present within China and usually distributed in disturbed habitats strongly influenced by human activities, the correlation between its genetic and geographic distance at population level suggests that some natural dispersal mechanism may also be involved in the distribution of this species. This distribution in China is unlike the population distributions in North America, where the populations were possibly originated very recent from a mixed origin (Jorgensen and Mauricio, 2004). However, it is impossible to trace the origin of the Chinese populations only based on the ISSR or RAPD data of these limited populations. Data on precise sequences from more populations worldwide will be needed to explore the origin of Chinese populations and their phylogenetic relationships with those from other parts of the world.

\section{Acknowledgements}

We thank Professors Bingyang Ding and Jianzhang Shao for providing information on the distribution of A. thaliana in China, and thank Ms Mengxin Xie for her technique assistance. We are very grateful to Professor Xiaoru Wang at the Swedish University of Agricultural Sciences and Dr Xiaoquan Wang at the Institute of Botany, the Chinese Academy of Sciences for their valuable comments and suggestions on this work. This work is supported by the State Key Basic Research and Development Plan (2006CB100105).

\section{References}

Al-Shehbaz IA, O'Kane SL (2002). Taxonomy and phylogeny of Arabidopsis (Brassicaceae). In: Somerville CR, Meyerowitz EM (eds). The Arabidopsis Book. Rockville, MD. Am Soc Plant Biol http://www.aspb.org/publications/arabidopsis149a, p 22.

Bakker EG, Toomajian C, Kreitman M, Bergelson J (2006). A genome-wide survey of $\mathrm{R}$ gene polymorphisms in Arabidopsis. Plant Cell 18: 1803-1818.

Barth S, Melchinger AE, Lubberstedt T (2002). Genetic diversity in Arabidopsis thaliana (L.) Heynh. investigated by cleaved amplified polymorphic sequence (CAPS) and inter-simple sequence repeat (ISSR) markers. Mol Ecol 11: 495-505.

Bartish IV, Rumpunen K, Nybom H (2000). Combined analyses of RAPDs, cpDNA and morphology demonstrate spontaneous hybridization in the plant genus Chaenomeles. Heredity 85: 383-392.

Bergelson J, Stahl E, Dudek S, Kreitman M (1998). Genetic variation within and among populations of Arabidopsis thaliana. Genetics 148: 1311-1323.

Breyne P, Rombaut D, Van Gysel A, Van Montagu M, Gerats T (1999). AFLP analysis of genetic diversity within and between Arabidopsis thaliana ecotypes. Mol Gen Genet 261: 627-634. 
Cheo T, Gue R, Lan Y, Lou L, Kuan K, An Z (1987). Arabidopsis. In: Cheo T (ed). Flora Reipublicae Popularis Sincae, Vol. 33. Science Press: Beijing, China. pp 281-287 (in Chinese).

Cheo T, Lu L, Yang G, Al-Shehbaz IA, Dorofeyev VI (2001). Brassicaceae. In: Wu Z, Raven PH (eds). Flora of China, Vol. 8. Science Press: Beijing, China; and the Missouri Botanical Garden Press: St Louis, USA. pp 120-121.

Diaz V, Muniz LM, Ferrer E (2001). Random amplified polymorphic DNA and amplified fragment length polymorphism assessment of genetic variation in Nicaraguan populations of Pinus oocarpa. Mol Ecol 10: 2593-2603.

Erschadi S, Haberer G, Schöniger M, Torres-Ruiz RA (2000). Estimating genetic diversity of Arabidopsis thaliana ecotypes with amplified fragment length polymorphisms (AFLP). Theor App Genet 100: 633-640.

Esselman EJ, Jianqiang L, Crawford DJ, Windus JL, Wolfe AD (1999). Clonal diversity in the rare Calamagrostis porteri ssp. insperata (Poaceae): comparative results for allozymes and random amplified polymorphic DNA (RAPD) and intersimple sequence repeat (ISSR) markers. Mol Ecol 8: 443-451.

Excoffier L, Smouse PE, Quattro JM (1992). Analysis of molecular variance inferred from metric distances among DNA haplotypes: application to human mitochondrial DNA restriction data. Genetics 131: 479-491.

Fontaine C, Lovett PN, Sanou H, Maley J, Bouvet JM (2004). Genetic diversity of the shea tree (Vitellaria paradoxa C.F. Gaertn), detected by RAPD and chloroplast microsatellite markers. Heredity 93: 639-648.

Hamrick JL, Godt MJW (1996). Effects of life history traits on genetic diversity in plant species. Philos $T$ Roy Soc B 351: 1291-1298.

Hanfstingl U, Berry A, Kellogg EA, Costa III JT, Rudiger W, Ausubel FM (1994). Haplotypic divergence coupled with lack of diversity at the Arabidopsis thaliana alcohol dehydrogenase locus: roles for both balancing and directional selection? Genetics 138: 811-828.

Hillis DM (1984). Misuse and modification of Nei's genetic distance. Syst Zool 33: 238-240.

Hoffmann MH, Glass AS, Tomiuk J, Schmuths H, Fritsch RM, Bachmann K (2003). Analysis of molecular data of Arabidopsis thaliana (L.) Heynh. (Brassicaceae) with Geographical Information Systems (GIS). Mol Ecol 12: 1007-1019.

Innan H, Terauchi R, Miyashita NT (1997). Microsatellite polymorphism in natural populations of the wild plant Arabidopsis thaliana. Genetics 146: 1441-1452.

Jorgensen S, Mauricio R (2004). Neutral genetic variation among wild North American populations of the weedy plant Arabidopsis thaliana is not geographically structured. Mol Ecol 13: 3403-3413.

King G, Nienhuis J, Hussey C (1993). Genetic similarity among ecotypes of Arabidopsis thaliana estimated by analysis of restriction fragment length polymorphisms. Theor Appl Genet 86: 1028-1032.

Koornneef M, Alonso-Blanco C, Vreugdenhil D (2004). Naturally occurring genetic variation in Arabidopsis thaliana. Annu Rev Plant Biol 55: 141-172.

Kuittinen H, Mattila A, Savolainen O (1997). Genetic variation at marker loci and in quantitative traits in natural populations of Arabidopsis thaliana. Heredity 79: 144-152.

Lapointe F-J, Legendre P (1992). Statistical significance of the matrix correlation coefficient for comparing independent phylogenetic trees. Syst Biol 41: 378-384.

Le Corre V (2005). Variation at two flowering time genes within and among populations of Arabidopsis thaliana: comparison with markers and traits. Mol Ecol 14: 4181-4192.

Lewontin R (1972). Apportionment of human diversity. Evol Biol 6: 381-398.

Loridon K, Cournoyer B, Goubely C, Depeiges A, Picard G (1998). Length polymorphism and allele structure of trinu- cleotide microsatellites in natural accessions of Arabidopsis thaliana. Theor Appl Genet 97: 591-604.

Mantel NA (1967). The detection of disease clustering and a generalized regression approach. Cancer Res 27: 209-220.

Mitchell-Olds T, Schmitt J (2006). Genetic mechanisms and evolutionary significance of natural variation in Arabidopsis. Nature 441: 947-952.

Miyashita NT, Kawabe A, Innan H (1999). DNA variation in the wild plant Arabidopsis thaliana revealed by amplified fragment length polymorphism analysis. Genetics 152: 1723-1731.

Nei M (1973). Analysis of gene diversity in subdivided populations. Proc Natl Acad Sci USA 70: 3321-3323.

Nagaoka T, Ogihara Y (1997). Applicability of inter-simple sequence repeat polymorphisms in wheat for use as DNA markers in comparison to RFLP and RAPD markers. Theor Appl Genet 94: 597-602.

Nordborg M, Hu TT, Ishino Y, Jhaveri J, Toomajian C, Zheng H et al. (2005). The pattern of polymorphism in Arabidopsis thaliana. PLOS Biol 3: e196.

Nybom H (2004). Comparison of different nuclear DNA markers for estimating intraspecific genetic diversity in plants. Mol Ecol 13: 1143-1155.

Parsons BJ, Newbury HJ, Jackson MT, Ford-Lloyd BV (1997). Contrasting genetic diversity relationships are revealed in rice (Oryza sativa L.) using different marker types. Mol Breeding 3: 115-125.

Qu L-J, Li L, Zhang Y, Liu M, Gu H, Chen Z (2000). Cloning and expression of a cDNA encoding ribosomal protein $\mathrm{S} 4$ from rice (Oryza sativa). Chin Sci Bull 45: 168-173.

Reisch C, Poschlod P, Wingender R (2003). Genetic differentiation among populations of Sesleria albicans Kit. ex Schultes (Poaceae) from ecologically different habitats in central Europe. Heredity 91: 519-527.

Rohlf FJ (1982). Consensus indices for comparing classifications Math Biosci 59: 131-144.

Rohlf FJ (2002). NTSYSpc: Numerical Taxonomy System, Ver. 2.1. Exeter Publishing, Ltd. Setauket, New York.

Schmid KJ, Torjek O, Meyer R, Schmuths H, Hoffmann MH, Altmann T (2006). Evidence for a large-scale population structure of Arabidopsis thaliana from genome-wide single nucleotide polymorphism markers. Theor Appl Genet 112: 1104-1114.

Sharbel TF, Haubold B, Mitchell-Olds T (2000). Genetic isolation by distance in Arabidopsis thaliana: biogeography and postglacial colonization of Europe. Mol Ecol 9: 2109-2118.

Stenoien HK, Fenster CB, Tonteri A, Savolainen O (2005). Genetic variability in natural populations of Arabidopsis thaliana in northern Europe. Mol Ecol 14: 137-148.

Tackenberg O, Poschlod P, Kahmen S (2003). Dandelion seed dispersal: the horizontal wind speed does not matter for long distance dispersal - it is updraft!. Plant Biol 5: 451-454.

The Arabidopsis Genome Initiative (2000). Analysis of the genome sequence of the flowering plant Arabidopsis thaliana. Nature 408: 796-815.

Ullrich H, Lattig K, Brennicke A, Knoop V (1997). Mitochondrial DNA variations and nuclear RFLPs reflect different genetic similarities among 23 Arabidopsis thaliana ecotypes. Plant Mol Biol 33: 37-45.

Vos P (1998). AFLP fingerprinting of Arabidopsis. Methods Mol Biol 82: 147-155.

Yang W, de Oliveira AC, Godwin I, Scheritz K, Bennetzen JL (1996). Comparison of DNA marker technologies in characterizing plant genome diversity: variability in Chinese sorghums. Crop Sci 36: 1669-1676.

Yeh FC, Yang R, Boyle T (1999). POPGENE, Version 1.32. Microsoft Window-Based Freeware for Population Genetic Analysis. University of Alberta: Edmonton. Available at: http:// www.ualberta.ca/ fyeh/index.htm. 